\title{
Aportes para la construcción de un modelo constitucional colombiano no hegemónico y sus condiciones de posibilidad desde la óptica del ejercicio del poder jurisdiccional
}
Jhonatan Harrys
Rodríguez Vesga ${ }^{1}$
Laura Cristina
Salazar Otero ${ }^{2}$

\section{jhonatanharrys@hotmail.com_laura.salazarotero@hotmail.com}

Artículo corto de investigación recibido el 28/04/2018

y aprobado el 31/07/2018

Cómo citar este artículo:

Rodríguez-Vesga, J., \& Salazar-Otero, L. (2018). Aportes para la construcción de un modelo constitucional colombiano no hegemónico y sus condiciones de posibilidad desde la perspectiva de la actividad jurisdiccional. Trans-Pasando Fronteras, (12).

\footnotetext{
${ }^{1}$ Abogado Universidad Santo Tomás de Bucaramanga, con experiencia en grupos y semilleros de investigación en estudios socio-jurídicos e interdisciplinares, así como programas radiales enfocados en educación, trabajo con grupos vulnerables y experiencia como citador de Juzgado civil municipal en la ciudad de Bucaramanga.

${ }^{2}$ Abogada Universidad Industrial de Santander, Especialista en Derecho Comercial UNAB, experiencia en semilleros de investigación de carácter socio-jurídica, Oficial mayor de juzgado civil del circuito del municipio de Bucaramanga.
} 


\section{Resumen}

El presente texto es un avance de investigación que se resolverá metodológicamente, desde tres momentos: El primero se ocupará de realizar una caracterización de algunos conceptos problemáticos y dogmáticos de la Constitución política colombiana, como el multiculturalismo, la idea de Estado-Nación y la forma en que se ejerce la democracia mediante el sistema de representatividad. En este mismo punto, se estudiarán algunas de las figuras más relevantes de la Constitución; aspectos que se analizarán desde las teorías transmodernas, decoloniales y posestructuralistas. Ello con el propósito de desentrañar su naturaleza e identificar posibles limitaciones en cuanto a su justificación y la forma en que estructuran política y jurídicamente al Estado y a sus instituciones centrales.En un segundo momento, se expondrá una "otra" teoría constitucional, originada en las teorías decoloniales y latinoamericanistas, que fundamentan sus enunciados en lecturas alternativas de la realidad, en las que se vincula la interculturalidad, el pluralismo jurídico y el poder constituyente como ejercicio creativo de la multitud y dinámica de inclusión de las subjetividades tradicionalmente excluidas. Examinando con tal propósito, aportes del constitucionalismo de países de América del Sur, a fin de encontrar cómo las ideas de la filosofía del derecho latinoamericanista se manifiestan en la materialización de algunas instituciones de países como Bolivia.Finalmente, una vez caracterizado este "otro" modelo constitucional, se hará un examen desde la perspectiva de la aplicación práctica de sus contenidos en la actividad jurisdiccional, planteando de qué manera, aunque estas teorías resulten más legítimas, podrían tornarse inaplicables en términos de eficiencia, lo que igualmente restaría legitimidad a un sistema incapaz de generar operatividad y proteger adecuadamente derechos de índole fundamental.

Palabras clave: Modelo constitucional colombiano; Teorías decoloniales; Institucionalidad; Pluralismo; Legitimidad; Actividad jurisdiccional. 


\section{Contributions for the construction of a Colombian non-hegemonic consti- tutional model and its conditions of possibility from the perspective of
the exercise of jurisdictional power}

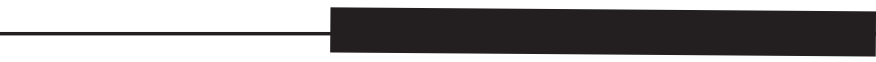

\section{Abstract}

The present text will be solved methodologically, from three moments: The first one will be in charge of making a characterization of some problematic and dogmatic concepts of the Colombian Political Constitution, such as multiculturalism, the idea of StateNation and the way in which democracy is exercised through the system of representativeness. In this same point, some of the most relevant figures of the Constitution will be studied; aspects that will be analyzed from the transmodern, decolonial and poststructuralist theories. This is for the purpose of unraveling their nature and identifying possible limitations in terms of their justification and the way in which they politically and legally structure the State and its central institutions.

In a second moment, an "other" constitutional theory, originating in decolonial and Latin Americanist theories, will be exposed, which base their statements on alternative readings of reality, in which interculturality, legal pluralism and constituent power are linked as an exercise. creative of the crowd and dynamics of inclusion of traditionally excluded subjectivities. Examining with such purpose, contributions of the constitutionalism of South American countries, in order to find out how the ideas of the philoso- 
phy of Latin American law are manifested in the materialization of some institutions of countries like Bolivia.

Finally, once this "other" constitutional model has been characterized, an examination will be made from the perspective of the practical application of its contents in the jurisdictional activity, stating how, even if these theories are more legitimate, they could become inapplicable in terms of efficiency, which would also reduce the legitimacy of a system that is incapable of generating operational capacity and adequately protecting rights of a fundamental nature.

Key words: Colombian constitutional model; Decolonial theories; Institutionality; Pluralism; Legitimacy; Jurisdictional activity.

\section{Caracterización de algunas de las figuras relevantes y conceptos problemáticos y dogmáticos de la Constitución política colombiana}

La constitución política colombiana de 1991, durante mucho tiempo fue considerada como uno de los elementos cumbres del pensamiento político y jurídico del país. El texto constitucional fue reconocido en el momento de su creación, como una herramienta para unir a los sectores disgregados por el conflicto y como una manera de reinventar aquellas instituciones republicanas que ya se veían vetustas y arcaicas, incapaces de solventar las necesidades del país.

Históricamente nace en el marco de una Colombia caracterizada por las guerrillas, los fallidos procesos de paz y el crecimiento expansivo del narcotráfico sustentaba económicamente la guer- 
ra. La constituyente fue vendida como un proceso inclusivo en donde todos estarían involucrados, una revolución que unía el pensamiento, la idiosincrasia de la actualidad del país en la formación de nuevas instituciones. Según Mejía (2010), revisando el proceso constituyente desde la óptica del procesalismo de Rawls, no existió realmente un consenso, ni mucho menos una discusión que ayudara a fijar las bases programáticas y los ideales de realización de las prerrogativas de la constitución, no existió ese dialogo nacional que realmente optimizara la caracterización de los problemas más profundos del país y la forma de resolverlos.

Para el autor en cita, lo que ocurrió fue que el pacto político resultante, se ubicó en el plano de lo ideal, y no en asuntos prácticos de resolución de las situaciones problemáticas que le dieron origen. Es así como el texto, adquiere un carácter ideal en el que las figuras de la democracia, el sistema de representatividad, la función social de la propiedad, el Estado Social de Derecho, no van más allá de ser promesas profundamente inconclusas.

Una constitución es desde la perspectiva de Carl Schmitt, una pugna de poderes, de potencias, es siempre una guerra, en donde se incluyen los pactos de poder; el vencedor sobre el vencido -por llamarlo de alguna manera-, consigna en el texto resultante, las huellas de ese enfrentamiento, en la mayoría de los casos las que le resultan más beneficiosas para el ejercer el poder. Esta idea podría denominarse como lo asume Negri (2015), una concepción irracional del poder, mediante estas pugnas se comienzan a configurar distintas/otras relaciones de poder derivado representadas en las instituciones y demás herramientas jurídicas que permiten a cierta oligarquía, ejercer el control obtenido por vía de las facultades que el mismo sistema les concede. Un ejemplo de ello es el concepto de multiculturalidad, se reconoce la coex- 
istencia de diferentes culturas y etnias, pero desde la idea de un alter distante, aquel que existe, pero que no tiene nada que aportar al dialogo que conforma a las instituciones del Estado, por lo tanto se produce un reconocimiento meramente formal-textual, que termina anulando las diferentes cosmovisiones en el ejercicio material de la politica. Marcada por un fuerte neo liberalismo, en la constitución se encuentra que el capitalismo y el dinamismo de la economía juegan a favor de la propiedad y la acumulación de riquezas, prácticas que la misma constitución faculta, mientras que en paralelo, se refiere a la necesidad de generar equidad, promover la solidaridad y favorecer la inclusión, contradicciones intrínsecas del sistema, paradojas que se van transformando en las diferentes etapas del capitalismo como lo sostendría Santos (1989) en la transición posmoderna del derecho y la política.

Sin embargo, no se quiere significar que la propiedad o la riqueza no sean necesarias para el desarrollo de un país; la propiedad es un elemento material que se enraíza en la cosmovisión de los pueblos, no es un mero concepto en abstracto, tiene amplia significancia en la vida de los hombres, la cultura y los procesos de identidad. Una economía social, significa que la riqueza debe servir para saciar esas grandes necesidades de la sociedad desde un ámbito material, que los derechos tengan una real eficacia, en tanto que de no ser de este modo, la constitución no sería más que un texto hueco y una excusa para la dominación soportada en una falsa paz, que oculta la violencia de tipo estructural, que justifica al sistema.

En este orden de ideas, la Constitución Política de 1991, significó un avance en materia de derechos; el enfoque multicultural y de pretensiones garantistas de la carta, facilitó la inclusión de un catalogo amplio de derechos de diferente índole, cuyo núcleo esencial serían los derechos fundamentales. Considerados bidi- 
reccionalmente, en un primer plano, como las garantías primordiales que tienen los habitantes del territorio colombiano y, en un segundo plano, como la base de protección sobre la cual deben dirigirse las políticas del Estado. Lo anterior tuvo lugar, debido a que en el ambiente de la constituyente pululaba la expectativa de realizar cambios profundos en la sociedad y en el aparato de poder del Estado; razón por la cual la carta fundamental que se entretejía en aquellas reuniones en las que se proponía satisfacer los intereses no sólo de índole política, sino también debía permearse de un sentido social el cual nunca llegó a tener. Asunto que podría evidenciarse en que ciertos grupos que no encajaban con la idea del Estado, fueran excluidos de la asamblea nacional, pensamientos diametralmente opuestos fueron subsumidos en las dinámicas de ocultamiento.

La constitución nace en un momento en el que las instituciones se vieron completamente arrodilladas por el flagelo de la guerra y el crecimiento exponencial de aquellas vertientes económicas que profundizaban los actos de la misma: masacres, pescas milagrosas, secuestros, voladuras de edificaciones, eran subsidiadas por toda una atmosfera de lo ilegal, razón ésta que hace pensar que este pacto político es realmente un pacto de guerra, que nace de la guerra, cuando de hecho hasta en el contractualismo más clásico, la paz es una idea fundamental para la conformación del Estado, y a la vez una exigencia para su sostenimiento. Aunque el planteamiento de la séptima papeleta fue movimiento de tinte democrático y reivindicador, concibió la constituyente como un proceso que se condensaba en ese texto político jurídico y dejó las discusiones del ámbito discursivo, como un evento pragmático de muy corta duración que realmente no fue un proceso inclusivo, comunicativo que lograse la comunión de opiniones en la concretización de las instituciones en democracia, ese proceso deliberativo entre la sociedad civil y el Estado. 
La idea de estado nación fue el espejismo que elevaba a nivel constitucional, ese ilusorio de cierta homogeneidad en el pensamiento colombiano. Esa muestra del gran plan del siglo XX por lograr una unificación de las identidades colombianas dentro de la idea de "Lo colombiano", como lo explica el profesor Castro (2000), proyectos articulados que buscan la conformación de una identidad nacional para desde allí impulsar programas homogeneizantes que aniquilan la diferencia. Así, el estado nación cuenta con instituciones centralistas, donde la soberanía aparentemente es del pueblo, pero realmente pertenece a aquellos que puedan dirigir económicamente a esas instituciones jerarquizadas y reproducidas por todo el territorio, alejando a las personas del real acceso a la decisión política, sobre lo que es pertinente o no hacer con su país o con sus recursos.

\section{Planteamiento y fundamentación de una "otra" teoría con- stitucional desde lecturas alternativas de la realidad y la ex- periencia del constitucionalismo en países de América del Sur.}

Un texto constitucional en términos de Ferdinand Lasalle, en un sentido clásico, es la unión de los poderes vivos de la sociedad, es el resultado de los pactos y alianzas que esta haga, es la forma mediante la cual una sociedad, se organiza ideal y materialmente estableciendo un orden sociológico y jurídico. En un sentido -aún muy contractualista-, el pacto en donde se manifiestan los deseos de la sociedad como resultado de un ejercicio de soberanía. Aunque no lo exprese como tal el autor, se entiende que en la constitución radica esa capacidad, la inmanencia del poder constituyente dentro de un texto.

En el caso de Schmitt, no existe la potencia sino el poder, es un asunto de amigo enemigo, es la confrontación, es la relación an- 
tagonista, acá la identidad se asume de manera negativa, el otro medido a la hechura del propio ser. Una diferenciación positiva de la identidad, asume que existen otras identidades y posturas, que no son malas en cuanto a la propia, sino que simplemente existen y se expresan de una manera diferente. La visión más positiva del poder, es la potencia desde el sentido Espinoziano, desde el cual, se asume a la misma como el núcleo central de la teoría de cuerdas del derecho constitucional latinoamericano. Como modelo explicativo, se aleja de la concepción rígida de la constitución como momento definitivo de la potencia, como consumación de la voluntad común, y permite entender al poder constituyente, como un poder al que es necesario retornar para a partir del mismo construir, interpretar y aplicar sus contenidos, en tanto que de no ser así, el sistema se convierte en algo ilegitimo, algo que no sirve para encontrar la equidad social ni la participación activa de los ciudadanos en las decisiones políticas.

La teoría de cuerdas del derecho constitucional expuesta por el profesor Boliviano Rojas Tudela (2012), es una "otra" teoría de tal naturaleza que permite una lectura plural del fenómeno constitucional, la cual se fundamenta en la interculturalidad y el pluralismo jurídico. Inicialmente lo que se toma de la teoría de cuerdas propia de la física es la idea de que existen diferentes universos y diferentes dimensiones. Las membranas de esos universos se encuentran en fluctuación, todo el universo está compuesto de partículas que conforman los átomos, estas partículas son como hilos circulares, como ligamentos que conforman absolutamente todo "son descritas como modos de vibración que tienen longitud pero no anchura ni altura, como fragmentos de cuerda infinitamente finos" como lo describe Hawkings (2010) en el gran diseño. Estas partículas conforman a su vez cuerdas, que podrían asimilarse a las cuerdas de una guitarra que están en constante vi- 
bración, lo que permite a los físicos imaginar que hay varios universos coexistiendo entre sí, las micro cuerdas son formas de energía que constituyen todo el espacio-tiempo formando membranas. El modelo que expone la teoría de las cuerdas puede describir a su vez el carácter dinámico de una narrativa constitucional cuyo sustento es la potencia de la multitud. La idea de que todo está compuesto de energía y que esa energía conforma diferentes universos, es decir pluriversos. Estos pluriversos componen la realidad social y esta realidad social se encuentra en un constante movimiento y expansión, en consecuencia se crea una dinámica, una potencia.

El concepto de potencia y poder constituyente son tomados de la lectura que Negri hace de Spinoza. Para Negri (2007) el poder constituyente en las democracias liberales y los sistemas políticos modernos tiene un papel fundacional sobre el Estado, cuyo cenit es la creación del texto Constitucional en el que concluye su labor y queda eclipsado por el poder constituido en donde el sistema de representatividad consume todo el papel que desempeña en el proceso jurídico-político. El poder constituyente formaba el ordenamiento, más no hacía parte de ella, no hacía parte de las fuentes jurídicas, sino que era únicamente la forma de generar una constitución, una nueva ideología que sirva para justificar el ejercicio hegemónico del poder, un tipo de ideología que se sobre expone sobre las demás y trata de ocultarlas o eliminarlas. A esta concepción se le puede anteponer una visión en la que el rol del poder constituyente sea protagonista, partiendo de la asunción de un nuevo sujeto político (la multitud) cuya naturaleza la define el movimiento, en oposición a la quietud del poder constituido. La potencia es la fuerza expansiva que introduce al colectivo de manera activa en la conformación del poder y las instituciones no solo de manera fundacional, sino constante e integral, como el motor que da vida a todas las dimensiones del pluriverso constitucional. 
Una idea constructiva del poder, no entendido como la capacidad de que otros hagan lo que el propio ego desee, sino, de construcción mutua posible es la que tenía Espinoza. Para Espinoza, no había un telos, un fin, un lugar a donde llegar ya que esa potencia de naturaleza social no es representable ni determinable, equivale a una red metafísica detrás del ser ontológico que abarcaba todas las relaciones que podrían manifestarse en la sociedad, podría decirse que esto es lo que constituye todo la realidad social, la potencia o energía, trabajo vivo en oposición a trabajo muerto, todo individuo tiene potencia, pero está en solitario se aísla, sucede lo contrario en comunidad, en donde el poder se multiplica.

Podría decirse que la Constitución como pacto político surge como resultado de la fluctuación de universos coexistentes y que por tanto contiene fragmentos dentro de sí propios de los elementos constitutivos provenientes de la multitud, de igual manera habrán de expandirse, desplegarse a toda la red social y al pluriverso constitucional, porque una constitución presente dentro de sí, una tradición heredada, proviene de una visión histórica que construye identidades, diversas, pero al fin de cuentas identidades, así que existen huellas para poder retornar a él, elementos interpretativos que nos ayudan a dilucidar situaciones concretas.

Estas narraciones son posibles a la luz de un nuevo modelo de Estado que incorpore un proceso político plural donde converjan diferentes concepciones del mundo, diferentes lenguas y lenguajes que permiten el descubrimiento de maneras diferentes de describir la realidad, mitologías, conceptos filosóficos, significantes y significados que al desenvolverse dentro del espacio cultural se escapan y se desarrollan fuera del entendimiento hegemónicoracional, es decir, de la lectura de la realidad que hace occidente, dando un giro al discurso hacia otras racionalidades. Tradiciona- 
Imente el Logos era la idea de razón y el mito de la irracionalidad, en el proyecto colonial, el mito era aquello que habría de ser erradicado, pero contrario a lo que se creía, el mito contiene dentro de sí elementos semióticos tan profundos, que dan cuenta sin saberlo y esperarlo, de los contenidos más profundos y significados de una sociedad, tal como lo refiere Uribe, D. B. (2009).

Es a través de un tipo particular de elementos que conforman el texto constitucional (indecibles) que es posible hacer una lectura múltiple, abierta a interpretaciones heterogéneas y diversos significados. Estos "indecibles", lo son en cuanto pertenecen a una realidad acontecimental, esto quiere decir, que son situaciones que no se tenían previstas antes de la formulación del texto y no se pueden comprender a partir de la lógica del mismo, ni de la dogmática jurídica que conforma el discurso hegemónico, por lo que deben ser complementados y traducidos de acuerdo al exterior constitutivo (poder constituyente, potencia de la multitud), Según Rojas Tudela (2012) a esto se le llama Exergo, una condición del discurso que apela al ritmo del discurso Ex(fuera) Ergon (de la obra) lo que quiere decir, que se encuentra dentro y fuera de la obra, el derecho es un conjunto capas, pliegues, es un tejido complejo e inteligible, siempre plural y múltiple que tiene siempre como norte la justicia.

Al igual que las cuerdas o los artículos que conforman la constitución son de naturaleza oscilante, mantienen una relación directa con el poder constituyente de poder constituido - exterior constitutivo, los artículos son de naturaleza oscilante, contienen dentro de sí elementos que guardan relación con aquel proceso que los creó, a esto se le llama tradición heredada, la posibilidad que hayan contenidos semióticos diversos detrás del texto, ideologías que sustentan otras ideologías, discursivas que fundamentan ampliamente el texto, como puede encontrarse en las constituciones 
Ecuatorianas y Bolivianas, en donde se entiende el constitucionalismo como un movimiento expansivo, así como se entiende la expansión del universo, se comprende que los conceptos dentro de la constitución son pragmáticos, deben ser contenidos sintéticos de reflexiones, los cuales habrán de volver a abordarse, siempre hacía la comprensión de las diferentes ideologías o cosmovisiones.

Para la interpretación de este tipo de texto se debe recurrir al poder constituyente, a la multitud o exterior constitutivo y a las memorias del constituyente como límite interpretativo para poner en marcha una "dinámica deconstructora" del texto constitucional que pasa de un estado de inmovilidad a uno de constante expansión de significados. De manera que leer un texto es siempre un despliegue, un abrir el texto a su multitextualidad. Realizar este despliegue es lo que Derrida, J. (1997) denomina deconstrucción. Método de raíz pos estructural que critica la corriente positivista al pretender la universalidad y las univocidad del derecho tanto en su construcción como en su interpretación, de manera que aparenta desarrollar sobre el mundo lo que Caputo, J. (2009) refiere como "un gigantesco juicio analítico".

La posibilidad de deconstrucción de la Constitución y el Derecho es cierta en tanto han sido construidos y constantemente se reconstruye debido a su naturaleza textual lingüística o estructural, lo que le permite una aproximación al ideal de "justicia", un imposible con el que jamás se identificará concretamente el texto constitucional pero al que habrá de aproximarse en cada situación en particular, dándole el impulso para reinventarse en su búsqueda.

A partir de lo anterior el profesor Rojas, F. (2012) plantea la deconstrucción como método de aproximación de la Constitución a la justicia, planteando los siguientes parámetros, i) texto constitucional como integridad, cada término se convierte en un concepto 
construido a partir de la intertextualidad. Los artículos como categorías conceptuales formadas por intertextualidad permiten su complementación a través de otros artículos ii) el exterior constitutivo, invocación/convocación del exterior constitutivo dentro de la interpretación del texto constitucional. Esta invocación/ constitución permite la conformación de la tradición constitucional como forma de historicidad, donde no solo se debe ver el texto constitucional sino aquello que está afuera de él como es el caso del proceso constituyente compilado en las memorias del constituyente; esto quiere decir, evaluar las verdades en su ser histórico. iii) la pluralidad en la interpretación, no se debe buscar una interpretación correcta que cierra, ya que la característica de la búsqueda de la justicia como parámetro de deconstrucción exige lo contrario, o sea, la apertura del texto.

La labor que convoca a las teorías constitucionales, que surgirán a partir de la reinvención del Estado en el acontecer del posconflicto, es crear fisuras en los códigos dominantes del sistema de normalidad y legalidad establecido en el texto constitucional. En palabras de Derrida J. (1997) se trata de plantear "la deconstrucción como una resistencia política ante cualquier forma de fascismo" Entendiendo fascismo como una forma de autoritarismo sustentado bajo sistemas herméticos que niegan las posibilidades de reflexión.

En este punto ya se ha perfilado una "otra" perspectiva teórica desde la cual se podría fundamentar un modelo constitucional, que dada su naturaleza de apertura a la pluralidad, es una alternativa viable en las sociedades latinoamericanas en razón a su historia política marcada por la negación de su diversidad, a esta propuesta teórica podría Ilamársele constitucionalismo latinoamericano porque piensa la Constitución desde un contexto local y bajo unas condiciones ontológicas determinadas por el mundo 
que acontece ante nosotros, lo que quiere decir que esta episteme se ubica en una geografía, historia y contexto particular, pero sin olvidar que vivimos en una realidad donde el ejercicio del poder se efectúa de manera transnacional, donde ocurren todo tipo de intercambios teóricos mediados por las reglas de producción económica e ideológica globalizada.

El modelo constitucional Boliviano se construye desde un enfoque que no es general ni particular, sino múltiple y complejo, y ya que por un lado, se aparta del modelo adoptado por la Constitución Política Colombiana de 1991, que es en palabras de Lascarro Castellar (2012), es un modelo que no piensa la Constitución, no la reflexiona ni construye sus conceptos, desde una visión del colonialismo jurídico, sólo la absorbe, incapaz de representar una alternativa al neoliberalismo y con una distintiva aceptación acrítica de este y sus contenidos, los que terminan por dar identidad a sus instituciones. El enfoque múltiple del modelo constitucional Boliviano se refleja en la existencia de instituciones como el Tribunal de Justicia Plurinacional y el órgano electoral de idéntica naturaleza, instituciones que deben su fundamentación a ideas que trascienden el puro reconocimiento de otras formas de justicia presentes en el territorio nacional, y conceden por esta vía a las mismas, un espacio dentro de la jurisdicción para el ejercicio de sus derechos.

Este problema genera la necesidad de inclusión y tratamiento jurídico de sus dilemas desde la intertextualización del texto constitucional, en palabras de Tudela, el derecho son capas y capas de diferentes contenidos que se pueden reinterpretar y se pueden reausumir desde diferente ópticas soportadas estas, en principios como el de interculturalidad, plurinacionalidad y complementariedad concebida como la integración de y entre todos, con sus individualidades, la sociedad y la naturaleza. 
En este último sentido, el pensamiento muta de una perspectiva antropocéntrica a una perspectiva eco céntrica. Los derechos de la pachamama según Zaffaroni, E. R. (2010), son derechos que reconocen a subjetividades no humanas como titulares de derechos, pero parten de allí, de esa filosofía. Constituciones como la Colombiana, marcadas por una fuerte raíz occidental mediantes ideas como el cristianismo, racionalismo o humanismo, que han trascendido desde la cultura, ven al hombre como el centro de las relaciones en la tierra y llegan a negar los derechos de las demás especies o a reconocerlos de manera muy taimada. Esta visión política y jurídica de la sociedad, también se desplaza hacia la economía, es una forma de lidiar con el capitalismo salvaje y con sus hondas repercusiones en el ámbito eco sistémico y poner obstáculos a una globalización desmedida, donde las brechas entre lo que es descrito como primer mundo y tercer mundo, se hacen más grandes. En esta pugna, los procesos de la economía tratan de salir de la relación de dependencia y llevar a cabo procesos que busquen la consecución de la soberanía de los pueblos coloniales, soberanía que no ha sido conseguida gracias a los procesos económicos tradicionales, que a la vez decantan en procesos culturales que adoctrinan a otras naciones, en una relación hegemónica de centro y periferia.

Uno de los elementos centrales de constitucionalismo latinoamericano acá expresado, es que a través de la desconstrucción busca la justicia; esta búsqueda entendida como la consecución de más derechos, la capacidad de cubrir más expectativas sociales. En la constitución de Bolivia, el catálogo de derechos va desde el artículo 13 a artículo 109, siendo en palabras de Rojas Tudela, una de las constituciones con más derechos del mundo. En donde se compaginan derechos de tipo fundamental, social, cultural, colectivos y el reconocimiento de los derechos de los pueblos indígenas, entre otros. Como se ha dicho, a diferencia de la concepción 
individualista de las constituciones del siglo XX, estas constituciones además de derechos individuales, tienen una concepción colectiva de los derechos, así derechos como el derecho a la salud, es visto como derecho a la salubridad, se entiende que hay una necesidad colectiva de sociedad a salud.

Otra diferencia marcada, es que tienen una fuerte raíz decolonial, la pregunta acerca del pensamiento situado se encuentra en sus raíces, así las instituciones y normas no tienen miedo a beber de sus propias máximas culturales y a la creación de nuevos conceptos a partir de asumir la textura abierta del lenguaje. Para autores como Dussel, la filosofía latinoamericana no se da únicamente desde el plano ideal, sino que por el contrario, ocurre en el orden de lo material, las reivindicaciones de derechos, aquellas que construyen ideologías, se dan por medio de revoluciones de carácter político. Así las cosas, se asume que los mecanismos constitucionales deben tener la manera de crear flujos y reflujos, movimientos centrípetas y centrífugos, que garanticen la participación de la sociedad en la construcción de las estructuras democráticas.

\section{Condiciones de posibilidad de un otro modelo constitucional en Colombia, desde la experiencia de la actividad jurisdiccional}

Los cuestionamientos de carácter ius-filosófico en el que se ven inmersos los jueces al momento de aplicar prerrogativas constitucionales, no puede ser solucionado mediante una respuesta intuitiva y reaccionaria por cuanto el juez, tiene la carga de argumentar y justificar sus decisiones, realizando un análisis juicioso de la cuestión que se le presenta. El funcionario judicial, en este caso el juez, se encuentra frente a un volumen de actuaciones, de matiz constitucional que habrá de resolver en un período determinado, las cuales se someten 
a las demandas y exigencias de los ciudadanos. Eso sin contar todas las otras actuaciones de tipo ordinario que tendrán que ser llevadas a cabo, so pena de alguna investigación disciplinaria.

La cantidad de procesos y el número de funcionarios judiciales, convierten a la justicia en un asunto pragmático que se resume a la eficiencia, lograr la aplicación normativa, principialistica, jurisprudencial a cada caso en concreto, teniendo en cuenta el número de actuaciones por resolver, el tiempo para fallar y el elemento humano disponible para llevar a cabo los procesos. Esta es una de las razones por las cuales el Derecho busca la homogenización de los mecanismos y la estandarización de los mismos, la sedimentación de los conceptos obedece a la necesidad de eficiencia en las resoluciones judiciales, es imposible para los funcionarios, generar reinterpretaciones absolutas en cada caso particular, aparte porque se termina minando una de las premisas básicas del ordenamiento: La seguridad jurídica como legitimadora de la actividad judicial. En un derecho constitucional como el Latinoamericanista, las normas procesales siempre deben ceder a la garantía de prerrogativas sustanciales y más si son del orden de derechos fundamentales. Este tipo de constitucionalismo, al tener un catalogo de derechos tan amplio, debe limitar los procedimientos para la concreción de un derecho fundamental, podría asegurarse que, establecer demasiados requisitos para la garantía de estos Derechos, torna a la actividad jurisdiccional en algo ilegitimo, pues pone demasiados requisitos a algo que de hecho ya está garantizado por el Estado y la constitución.

Lo que se observa como funcionario judicial, es que muchas de las actuaciones constitucionales de carácter judicial, se originan en la incapacidad del Estado en cumplir vía administrativa los derechos de índole fundamental y social, y además porque no se ha logrado que los ciudadanos conciban la necesidad de la realización de los 
derechos de diferente índole, para la consecución de la convivencia social, desde este plano la jurisdicción tiene un sentido reivindicatorio de derechos fundamentales y no meramente formal y probatorio.

Si la idea de derecho constitucional que se tiene, es la latinoamericanista, esto es, un Derecho constitucional expansivo, e intertextual, se supondría que el derecho procesal, debería ser reducido a su mínima expresión, y en todo caso de existir, debe ser igualmente intertextual y reconociendo e integrando otras soberanías, inclusive naciones, idea que escapa a la rigida concepción del Estado-nación unitario donde los ciudadanos se identifican como parte de un solo pueblo.

Igualmente desde esta perspectiva, se hace igualmente necesario integrar otros procedimientos para llevar a cabo la realización de la justicia. Si el procedimiento se diversifica se hace más legítimo, construyéndolo como un ejercicio de la potencia, no como producto ni de la colonización ni del trasplante jurídico, sino de la creación situada. Nos encontramos pues, con un procedimiento intertextual de muchas aristas, ya que ese procedimiento, debería tener en cuenta el caleidoscopio de las justicias, la visión de justicia de las comunidades que son minorías y que han sido tradicionalmente excluidas.

Un procedimiento heterogéneo y contrahegemónico por más legítimo que sea, por más que se construya desde la radicalidad de la diferencia, podría tornarse altamente ineficiente, cosa que también termina siendo un peligro para el sistema, pues la comprensión del derecho variaría facilmente según la territorialidad y la cosmovisión, es como pensar que en Colombia existiese un derecho diferente para cada región un derecho que aunque da muestra de la identidad particular de las sociedades, puede recaer en la superproducción normativa, ahogar los derechos en mares de tinta y de papel. 
Aunque el derecho es producto de la cultura, lo que quiere decir que proviene de codigos de significancia sociales, de normas morales, de costumbres, es un artificio complejo, por eso se le disecciona y se le divide como el conocimiento, por disciplinas. Así las cosas, con ese grado de dificultad con un derecho procesal que tiende a la apertura, a la reinvención, la actividad jurídica se convierte en un asunto de eruditos y no en una forma de resolver necesidades y expectativas sociales de manera practica y material. Igualmente cabe decir que, paradójicamente los lineamientos procesales en temas tan sensibles como la tutela, ayudan a que el sistema no colapse, al no existir una educación en el uso racional del sistema judicial, la cantidad de tutelas que se presentan a diario es desbordada, muchas veces sin una razón de peso que le justifique y muchas veces debido a la falta de educación a las personas en asuntos constitucionales, educación que debería ser parte de la pedagogía de la formación del ciudadano, cosa que de hecho es un mandato de la carta política del 91. Esta alarmante cantidad de trámites constitucionales a la que se exponen los despachos, pueden generar congestión y ineficacia de las instituciones jurídicas, un sistema que no funcione o que deba explotar a sus operadores para llevar a cabo sus fines, es un sistema igualmente ilegitimo.

El constitucionalismo Latinoamericano nos dice que es posible alejarse de la norma, en favor de conseguir el ideal principal del derecho que es la justicia, sin embargo las decisiones que se apartan del modelo y se encaminan a satisfacer interpretaciones alternativas, profundas, contra sistémicas; en términos prácticos equivale a mayor tiempo de los funcionarios y menor número de resultados, los cuales deben probarse trimestralmente para mantener la existencia del juzgado y a la par, el mantenimiento de las familias de los operadores, por tanto deben acreditar estadísticamente su rendimiento, medido de forma numérica y no cualitativa. 
Aunado a lo anterior, el sistema jerárquico jurisdiccional logra cercar aquellas decisiones que aunque justas se alejan del sistema constituido, los jueces y funcionarios judiciales se fijan en demasía del procedimiento, porque es la manera de evitar nulidades y sanciones, cuando un trámite ingresa a segunda instancia por impugnación por ejemplo, el superior jerárquico se encarga de corregir esos yerros, el sistema se encarga de volver a encauzar aquello que puede llegar a ser revolucionario, o contra statu quo, dentro de los causes de la burocracia y el sistema constituido. Aparte porque pueden existir decisiones justas y revolucionarias, como atropellos, infracciones y delitos.

\section{Conclusiones}

Según lo sustentado, la carta política de 1991 es una constitución que nace de la guerra, de la pugna de poderes que deja como resultado un texto altamente neoliberal, en donde las instituciones funcionan con arreglo de la economía y por ende, al existir dentro del marco de un capitalismo transnacional, la sociedad se organiza de manera inequitativa y desigual, donde la protección a la idea de propiedad juega un papel muy importante. La constitución altamente idealista, no de metas programáticas, sino plagada de ideales y valores abstractos, no logra dar soluciones sustanciales a los problemas de la sociedad, no solo por su aplicación, sino por la naturaleza del texto mismo; que no es una reconstrucción de la heterogeneidad del pensamiento social, político y jurídico del Estado Colombiano, sino la asunción de ciertas visiones de poder, que vienen encumbradas por algunas oligarquías, linajes familiares y círculos sociales que no permiten la intromisión de otras ideologías en el espectro constitucional jurídico. 
Esto por supuesto, no obedece únicamente a dinámicas nacionales, sino que proviene de toda una idea de organización mundial y transnacional, que es alimentada por una economía en donde pareciese que las democracias son sistemas serviles a la acumulación y a la desigualdad, a la destrucción de los territorios y el ecosistema, a la homegenización y estandarización de los saberes que aniquila la diferencia, al colonialismo político y jurídico, en donde el estado como parte del capitalismo integrado, permea para destruir o apropiarse de aquellas reterritorializaciones que los individuos como sociedad tratan de llevar a cabo, algunas manifestaciones a modo de violencia epistémica y estructural y otras más radicales como el asesinato por ejemplo, de líderes sociales que luchan por los derechos de sus comunidades.

Resulta por tanto, insuficiente la visión constitucional que se alberga en la carta del 91, porque al texto ser extremadamente abstracto e idealista, permite que los grupos de poder lo interpreten de tal manera que aquellas violencias sociales logran perpetuarse mediante la desigualdad, que garantiza que no exista transito social, sino que los pobres sean cada vez más pobres y los ricos cada vez más ricos, una visión que da concesiones a las grandes empresas pero aniquila formas alternativas de economía, por ejemplo la economía ecológica y agrícola, que lucha por la sostenibilidad alimentaria de los estados y lo que se consigue, es acomodar a los países en un ordenamiento global de intercambio en donde las condiciones de crecimiento son muy desiguales.

La visión de los modelos constitucionales latinoamericanos trata de oponerse a esa idea de homegeneidad, intenta introducir dentro de los códigos de significación totalitarios, ideologías que reproducen la diferencia de manera exponencial, porque es consciente del colonialismo económico, jurídico e ideológico, al que son expuestas 
las naciones de Suramérica. Más allá de realizar textos ideales que postulan derechos, que por cierto son confeccionados con arreglo a cierta identidad cultural, se le trata de dar contexto y aplicación a las realidades que encarna la sociedad dentro del marco de la institucionalidad del Estado, permitiendo con ello una construcción legítima del orden legal y del poder constitucional a partir de la incorporación de nuevas lecturas de la sociedad civil que es la que debería dar origen y sustento al esquema político del país.

La idea de centralización, el paradigma hegemónico y las visiones totalizadoras, perderían fuerza en un contexto social cada vez más diverso, en el que las fronteras y vacíos deben ser abordados desde una amplia visión que dé cabida a actores diversos y tradicionalmente excluidos, una visión que trascienda del texto constitucional y pueda aplicarse a la realidad que la origina en un dialogo de complementarización entre lo que está en el texto y lo que está fuera de él, haciendo que las instituciones se construyan desde la potencia creativa, esto quiere decir que la sociedad debe tener injerencia en las decisiones del estado y no solamente una injerencia formal, de reconocimiento, sino material y de cambio, por tanto, ideas como las de las consultas populares, deben ser incentivas y fortalecidas.

El acercamiento del poder político institucionalizado a la realidad del país, implica un desafío en términos de sostenibilidad financiera y seguridad jurídica, ello en tanto que exige la creación y sostenimiento de modelos de aplicación de justicia alternos; demanda del funcionario un desmonte de la visión totalizadora del texto de la ley para aplicar el contexto de la realidad social de la norma; exige mayor determinación en la toma de decisiones judiciales que se aparten del precedente, lo que encuentra limitaciones en el respeto y respaldo institucional de tales disposiciones, al interior de un sistema judicial por naturaleza jerárquico en el que predomina 
la falta de apoyo a las posturas que se arriesgan al dejar de lado la seguridad de una decisión legalmente correcta, por adoptar una legítimamente aceptable. Por tanto, se tiene que existe un modelo constitucional que resulta vetusto y poco significante ante la expectativa de nuestro tiempo, pero esto, sólo en términos teóricos, ya que la respuesta no se halla en la constitución en sí, sino en la sociedad; realizar un nuevo texto constitucional no es una antídoto a los problemas del país, sino es reafirmar ese tipo de respuestas apresuradas que terminan siendo ineficaces e incapaces, la sociedad debe reconstruirse y abrir espacios que permitan el quebrantamiento a los códigos de significación dominante, y esto también, debe suceder dentro de las instituciones, ya que son las personas las que las encarnan y les dan movimiento y vida.

Las tesis latinoamericanistas a nivel ideológico crean figuras y fisuras, en esa idea de ordenamiento mundial con fines totalitaroas, propenden por la liberación y la legitimidad de los sistemas, aunque esa apuesta radical por la diferencia puede chocar o ir en contra vía de la operatividad de los sistemas, es una apuesta más que necesaria de parte de los países latinoamericanos, necesitan reconstruirse desde un pensamiento situado, sino que simplemente, en las condiciones actuales, la operatividad de esos modelos pareciese un ideal inalcanzable por las condiciones materiales de su creación; por tanto, una de las tareas pendientes del constitucionalismo latinoamericano, es comenzar a pensar desde allí, desde la operatividad y la concreción de las instituciones que incluyan y permitan la participación de los diversos actores de la sociedad en la vida jurídica y política del país, pero no una participación abstracta sino directa, canales que permitan a la sociedad la corrección y creación de nuevas instituciones, esto inclusive, en el marco del Estado actual, con la constitución vigente. 


\section{Bibliografía}

Castro, S. (2000). Ciencias sociales, violencia epistémica y el problema de la invención del otro. La colonialidad del saber: eurocentrismo y ciencias sociales. Perspectivas latinoamericanas, 145-163.

Castro Gómez, S., \& Restrepo, E. (2008). Genealogías de la colombianidad: Formaciones discursivas y tecnologías de gobierno en los siglos XIX Y XX. Bogotá: Pontificia Universidad Javeriana.

Caputo, J. (2009). La deconstrucción de una cáscara de nuez. Prometeo Libros.

Derrida, J. (1997). Fuerza de Ley. Madrid, España: Tecnos.

Hawking, S. (s.f.). El gran diseño. Barcelona: Crítica Barcelona.

Negri, T. (2007). El poder constituyente. En T. Negri, Imperio, multitud y sociedad abigarrada (p.p. 103-111). Sucre, Bolivia.

Negri, A. (2015). El poder constituyente. Ensayo sobre las alternativas de la modernidad. Journal of Modern History, 11, 481.

Quintana, O. M. (2010). La constitucionalización de la mentira. Dominación y exclusión en la constitución de 1991. Espacio crítico.

Rojas, F. (2012). Hacia una nueva gramática constitucional. (I. d. UNAM, Ed.) Crítica Jurídica (34), 95-121

Santos, B. d. (1989). La transición postmoderna del derecho y la política. Doxa.

Uribe, D. B. (2009). América latina frente a la posmodernidad: Análisis y perspectivas. Cuadernos de filosofía latinoamericana.

Zaffaroni, E. R. (s.f.). La naturaleza como persona: Pachamama y Gaia. Vicepresidencia del estado, Presidencia de la asamblea legislativa plurinacional. 